\title{
Wrongful deaths and rightful lives - screening for Down syndrome
}

\section{Frank Buckley and Sue Buckley}

Prenatal screening for Down syndrome affects millions of pregnancies every year worldwide. The vast majority of screen-positive results are false, yet encourage invasive diagnostic procedures that pose additional risks to unborn babies. As a direct consequence many babies who do not have Down syndrome are lost. We estimate that current screening practice in England and Wales reduces annual live births of babies with Down syndrome by around 660 and leads to the losses of 400 babies without Down syndrome. Although prenatal diagnoses are becoming more frequent, more babies with Down syndrome are being born (up $25 \%$ over 15 years). Considerable attention has been given to studying the performance of competing screening techniques, yet relatively little attention has been given to the consequences for the psychological and physical wellbeing of all parents and their babies. Meanwhile, quality of life for people with Down syndrome continues to improve. In many countries, people with Down syndrome are living longer and achieving more than ever before. The authors urge policymakers to note that the live birth prevalence of Down syndrome continues to rise and that average life expectancy is now approaching 60 years. Accordingly, research and practice priorities should shift from prevention to improving care, education and support for a growing and ageing population. We suggest that policies permitting genetic screening for mental or physical abilities should be reviewed through wide public debate before new prenatal diagnosis and genome sequencing technologies become more readily available.

The American College of Obstetricians and Gynecologists is recommending that all pregnant women in the USA be offered prenatal screening before 20 weeks $^{[1]}$ with a preference for first trimester screening ${ }^{[2]}$. Earlier this year, the UK National Institute for Health and Clinical Excellence (NICE) recommended that all women be offered the first trimester combined test, including an ultrasound examination and blood tests (News, p.89; REF 3). In Scotland, it has recently been announced that the combined test will be made available to all pregnant women by March 2011.

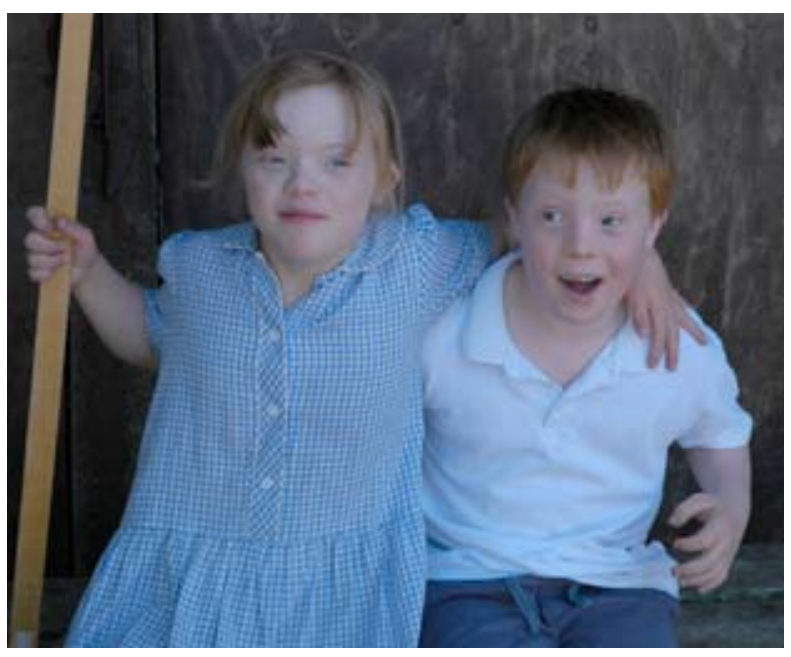

ern prenatal screening practices and some of their consequences for today's parents (Essay, p.118). These experiences do not appear to be unusual. The UK National Institute for Health and Clinical Excellence's recently updated review concluded that there is "high quality evidence to indicate that pregnant women do not have sufficient knowledge to make the informed decisions that need to be made regarding Down's syndrome screening"[3]. Some healthcare professionals appear to misunderstand screening test peting screening methodologies ${ }^{[3]}$. There has been comparatively little research that examines the extent to which these processes assist informed decision making in practice and how they affect the overall wellbeing of parents and their children ${ }^{[3,4]}$. Less research has examined the quality of life as experienced by people with Down syndrome and the extent to which the additional challenges they face are necessary consequences of their condition ${ }^{[4-6]}$.

In this issue we publish a mother's personal account of her experiences of mod- results $^{[7]}$ so it may not be surprising that many pregnant women "find the concept of risk calculation particularly difficult to understand"[3]. Counselling may be unduly negative about the likely quality of life for people with Down syndrome $^{[8]}$. Reports from mothers of children with Down syndrome in Spain and the USA suggest widespread failings in the care and support offered those receiving a diagnosis of Down syndrome $e^{[9-11]}$.

Current screening practice may also be adversely affecting maternal bonding ${ }^{[3,12]}$, 


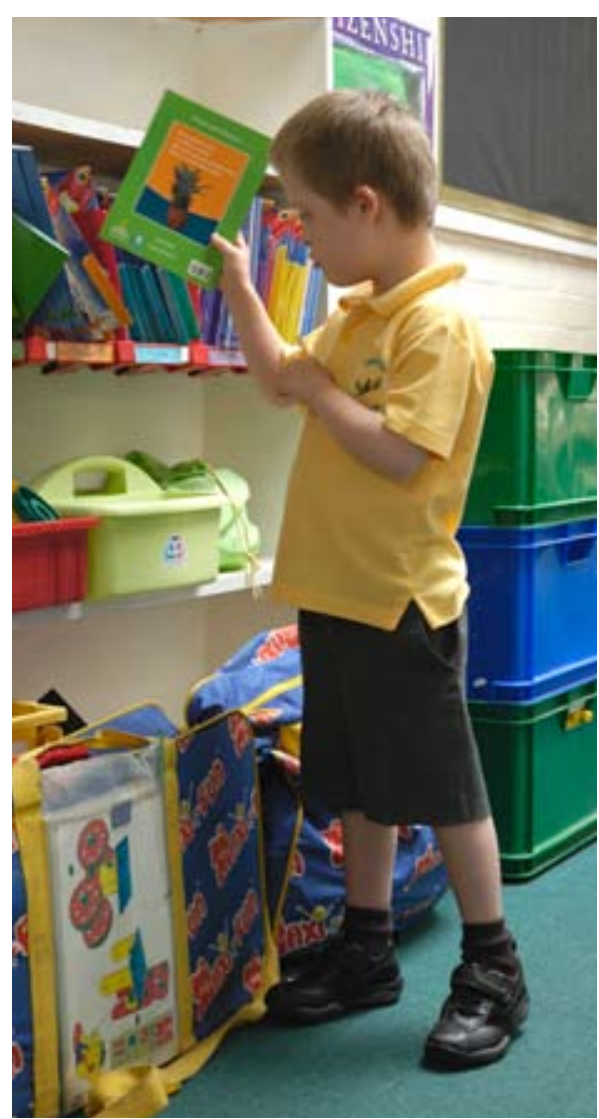

causing anxiety to mothers that is detrimental to their babies' development ${ }^{[13,14]}$ and leading to undesirable psychological consequences for some couples choosing selective terminations ${ }^{[15]}$. These adverse effects of prenatal screening have not been investigated as rigorously as competing screening techniques ${ }^{[3]}$.

The human and economic costs of screening are often contrasted against the 'burden' and 'distress' caused to families by the presence of a child with Down syndrome ${ }^{[4]}$. Yet, studies of families with children with Down syndrome have found that most cope well and report benefits as well as challenges associated with having a child with Down syndrome ${ }^{[16]}$. Studies also find positive effects for many brothers and sisters growing up with a sibling with Down syndrome ${ }^{[16,17]}$.

Prenatal screening offers a large annual market for suppliers of tests and associated services. Currently, Down syndrome would affect an estimated 1 in 500 live births in England and Wales in the absence of screening. However, the potential market for screening tests includes all of the approximately 700,000 annual pregnancies in England and Wales. Many of the biochemical markers used in screening are the subject of patents. Concerns have been noted about the roles of individuals in screening research and policy formula- tion holding such patents or having interests in organisations providing screening related services and software ${ }^{[4,18,19]}$.
"The main drive towards introducing screening appears to come from medical agencies, not from lay people or through democratic debate; there has been no parliamentary discussion or law on screen- ing in Britain. Policies are formulated by advisory committees, which issue guidance. Medical reports emphasize the prevention of suffering and promotion of parental choice by offering termination of affected pregnancies. Public health reports stress economic aims: to reduce the 'life time costs of care' for people with Down's syndrome; to avoid costly litigation for 'wrongful birth' of undiagnosed babies; and to develop comparatively cheaper, although also profitable, screening technologies." ${ }^{\text {"[4] }}$

So what are the facts about current screening practices?

\section{Prenatal screening in theory}

Maternal age is a clear predictor of the risk of delivering a baby who has Down syndrome $^{[20]}$ (FIGURE 1). Historically, invasive diagnostics were offered to mothers aged over 35 years $^{[21]}$ for whom maternal age alone indicated that the chance of delivering a baby with Down syndrome to be greater than 1 in 350 . For these mothers, the chance of delivering a baby with Down syndrome may be similar to the risk of losing an unaffected baby as a result of the diagnostic procedure. The 'rationale' to this approach was that as long as the chance of giving birth to a baby with Down syndrome is near to or greater than the risk of losing an unaffected baby, then an invasive diagnostic procedure is 'worthwhile'.

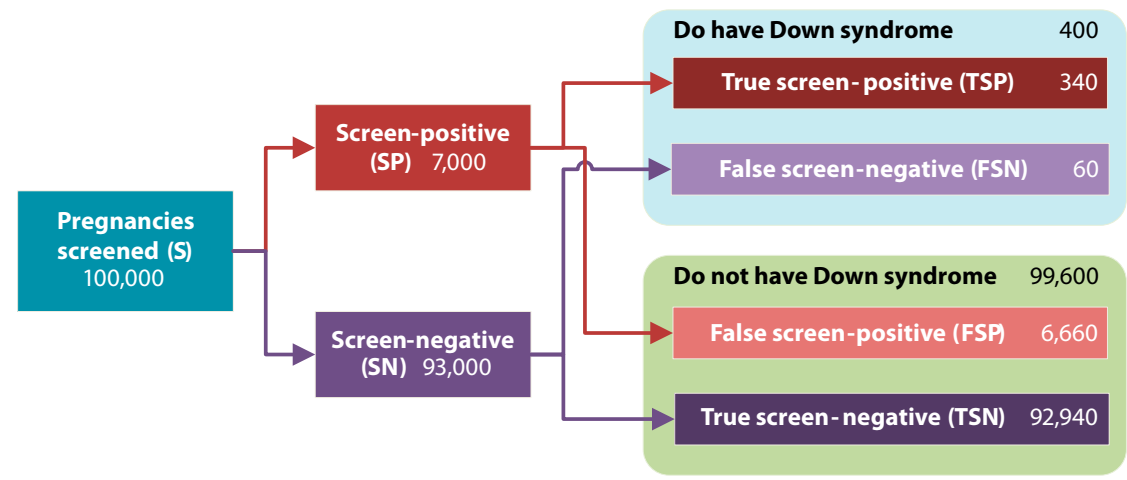

Figure 2 | The screening process, possible outcomes and measures of accuracy. Detection rate: The proportion of cases with the condition correctly identified by the screening test: TSP $/($ TSP + FSN $)=85 \%$. False positive rate: The proportion of cases without the condition incorrectly identified as positive by the screening test: FSP / (FSP + TSN) = $6.7 \%$. Odds of being affected given a screen-positive result (OAPR): The ratio of true screen-positives to false screen-positives $=1: 20$. (Illustrative figures. For further discussion of terminology, see REF 24) 
a

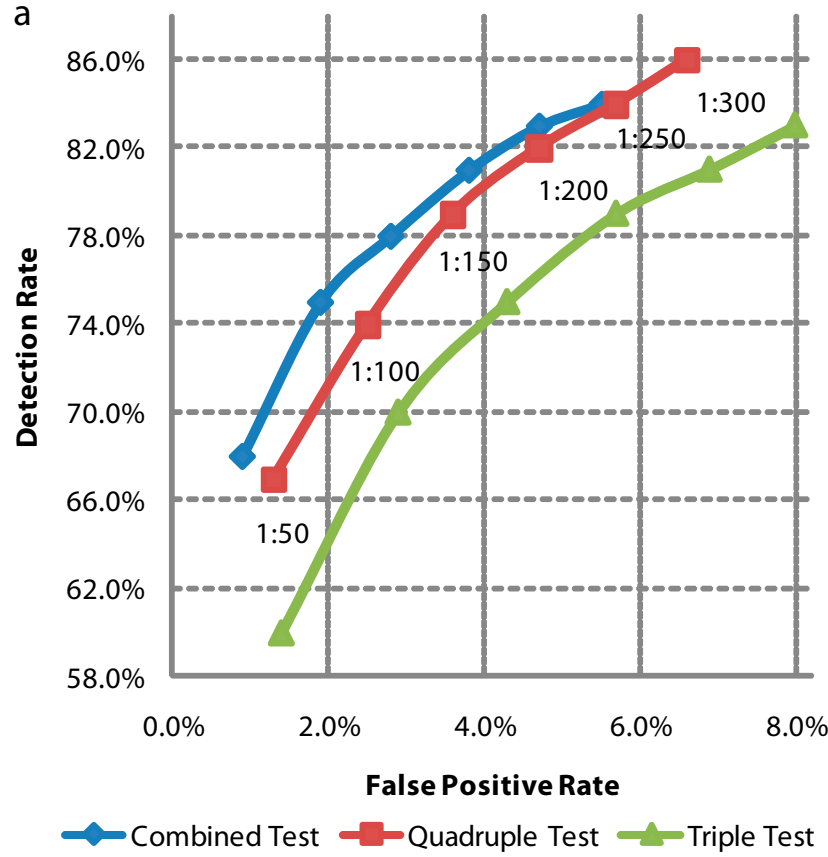

b

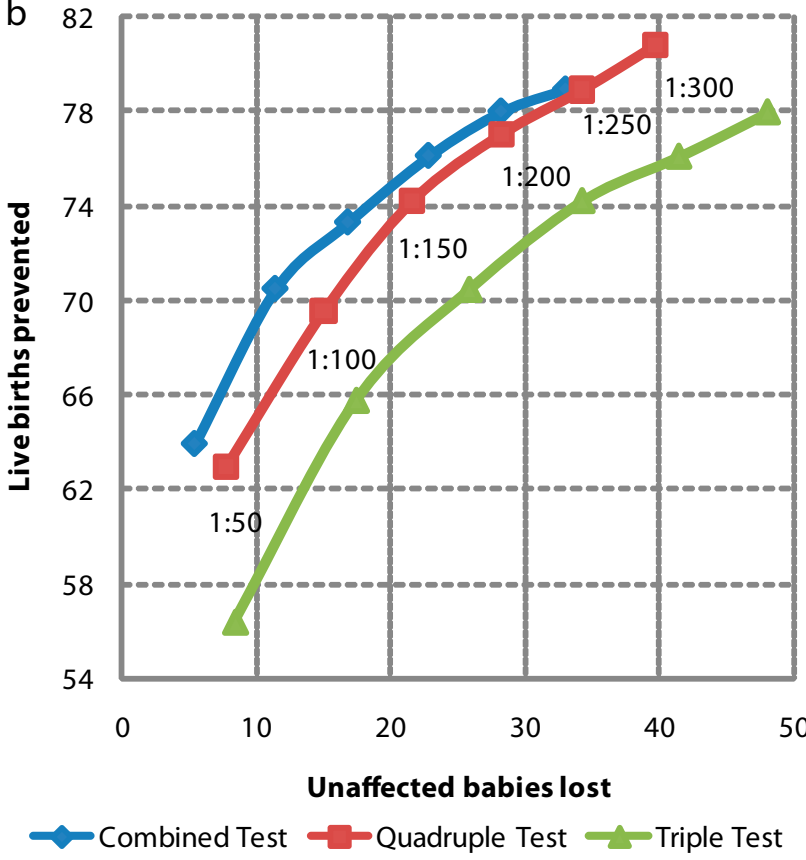

Figure 3 | Choosing between detection and false positive rates with risk cut-offs. a Higher detection rates imply higher false positive rates. The balance is selected by the 'cut-off' used to distinguish between 'high' and 'low' risk results. b Only around 1 in 30 to 1 in 20 screen-positives correctly identify an affected pregnancy, encouraging many women with unaffected pregnancies to accept invasive diagnostic procedures leading to the loss of some of these babies. The selection of cut-offs is a choice between affected live births prevented and unaffected babies lost. (Prevalence, detection and false positive rates as predicted for an early second-trimester cut-off in REF 20 and applied to an illustrative 100,000 pregnancies, assuming $60 \%$ of those receiving screen-positives choose diagnosis and $90 \%$ of pregnancies diagnosed with Down syndrome are terminated and a natural foetal loss rate of $23 \%)$.

testing. There are, therefore, four possible screening outcomes: true screen-positives, false screen-positives, true screen-negatives and false screen-negatives (FIGURE 2). Mothers receiving screen-positive results are encouraged to consider invasive diagnostic testing. As these procedures risk the loss of the pregnancy, screening policies aim to minimise false screen-positives. At the same time, they seek to maximise detection rates.

The 'risk cut-off' chosen to distinguish between screen-positives and screen-

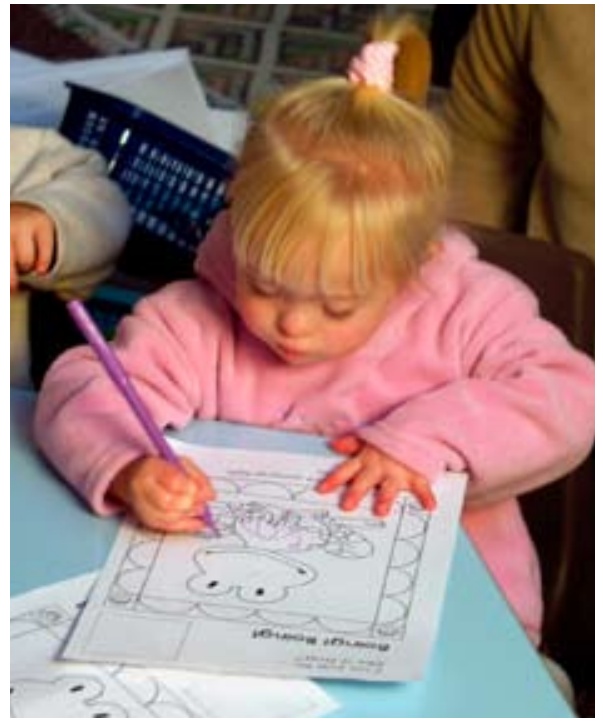

negatives is therefore an essentially arbitrary choice of where to balance detection rates and false positive rates (FIGURE $3 \mathrm{~A}$ ). A higher risk cut-off reduces false screenpositives but also reduces the detection rate (and vice versa), influencing both the number of affected babies born and unaffected babies lost (FIGURE 3B). This model holds given a fixed proportion of women choosing invasive diagnosis following a screen-positive test result irrespective of individual estimated risk. In practice, women who have chosen prenatal screening may be more inclined to opt for invasive diagnosis when given a higher estimate of risk $^{[25]}$.

\section{Distinguishing between detection and prevention}

The presence of an unusual number of chromosomes is surprisingly common among human conceptions - affecting perhaps $20 \%$ of all fertilised eggs ${ }^{[26]}$. Many fail to survive during the early weeks of pregnancy. Pregnancies affected by Down syndrome are substantially more likely to miscarry naturally than unaffected pregnancies. Studies have reported differing estimates of the rates of pregnancy loss. A summary estimate suggests that $43 \%$ of babies diagnosed with Down syndrome at around 11 to 13 weeks gestation and around $23 \%$ of those diagnosed at around 16 to 18 weeks naturally fail to survive to live birth ${ }^{[27]}$. Loss rates appear to be higher among older mothers ${ }^{[28]}$. It is difficult to establish precise figures in the absence of studies including a large population of prenatally diagnosed pregnancies with complete follow-up. It seems probable that miscarriages are more often underreported than terminations or live births. Pregnancies affected by Down syndrome that are not prenatally detected (false screen-negatives) and do not result in a live birth are also not included and represent another source of bias in comparisons of prevalence at different gestations and live births (and in the calculation of published detection rates).

The natural loss rate means that prenatal detection and termination is not the same as live birth prevention (as many of those terminated would not have survived if left alone). The natural loss rate also means that screening earlier in pregnancy (for example, by adopting the first-trimester combined test) will detect proportionally more affected pregnancies that would not have naturally survived, therefore substituting terminations for miscarriages in many cases. 


\section{Estimating risks to unborn babies}

The best available evidence suggests that the risk of pregnancy loss due to amniocentesis is $1 \%^{[29-33]}$ and that loss due to firsttrimester chorionic villus sampling (CVS) is $2 \%{ }^{[33,34]}$. There are wide variations in the rates of complications observed following both ultrasound guided amniocentesis and $\mathrm{CVS}^{[30]}$. Studies have observed loss rates following amniocentesis that are 6 to 8 times higher among less experienced practitioners than among experienced practitioners $^{[31]}$.

Given the uncertainty about the precise safety of amniocentesis and CVS, the authors find it surprising that only the outcomes of pregnancies diagnosed with Down syndrome are systematically recorded in England and Wales. A public audit of outcomes for all pregnancies following invasive diagnostic procedures would give a clearer picture of overall loss rates among unaffected pregnancies and would identify variations in performance.

Policies leading to increased first-tri- mester screening (and therefore diagnosis by CVS ${ }^{[2,3]}$ may substantially increase the numbers of unaffected babies lost (without corresponding reductions in the false positive rate).

\section{Performance in practice}

Many published studies of competing screening technologies model the effects of differing risk cut-offs. Modelling may or may not be representative of performance in practice. For example, the predicted performance of quadruple test screening shown in FIGURE 3 at a risk cut-off of $\geq 1$ in 300 was an $86 \%$ detection rate for a $6.6 \%$ false positive rate ${ }^{[22]}$. By contrast an audit of quadruple test performance in $14 \mathrm{UK}$ hospitals observed an $81 \%$ detection rate and for a $7 \%$ false positive rate, given a risk cut-off of $\geq 1$ in $300^{[35]}$. These modest differences equate to 2 additional unaffected babies lost and 5 fewer affected live births prevented for every 100,000 pregnancies screened. Other studies also illustrate how outcomes in practice may differ from some models ${ }^{[36,37]}$.
In the UK and many parts of Europe, prenatal screening has been offered to most women, regardless of age, for the past decade ${ }^{[38-40]}$. In England and Wales, prenatal screening has been available since the end of the 1980s. The National Down Syndrome Cytogenetic Register (NDSCR) has maintained records of diagnoses and pregnancy outcomes since 1 January 1989 and has recently published data for $2006^{\text {[REF 39]. }}$.

We have analysed the data recorded by the NDSCR to estimate the performance of prenatal screening policies in England and Wales for the fifteen years from 1992 to 2006 (TABLE 1). NDSCR records data for all pregnancies diagnosed with Down syndrome prenatally and at birth in England and Wales ${ }^{[39]}$. We apportioned unknown outcomes in line with known outcomes to provide a complete estimate of live births, miscarriages/stillbirths and terminations. We then estimated the number of live births prevented by subtracting predicted natural losses from the pregnancies that were terminated (assuming natural foetal

\begin{tabular}{|c|c|c|c|c|c|c|c|c|c|c|c|c|c|}
\hline \multirow[t]{3}{*}{ Period } & \multirow{3}{*}{$\begin{array}{r}\text { All Live } \\
\text { births } \\
\text { LB } \\
n\end{array}$} & \multirow{3}{*}{ 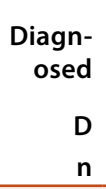 } & \multirow{2}{*}{\multicolumn{2}{|c|}{$\begin{array}{r}\text { Prenatally } \\
\text { diagnosed } \\
\text { PD }\end{array}$}} & \multirow{3}{*}{$\begin{array}{r}\text { Termin- } \\
\text { ated } \\
\mathbf{T} \\
\mathbf{n}\end{array}$} & \multirow{3}{*}{$\begin{array}{r}\text { Miscarried } \\
\text { or stillborn } \\
\text { M } \\
\mathbf{n}\end{array}$} & \multicolumn{2}{|c|}{ Live births } & \multirow{3}{*}{$\begin{array}{r}\text { Natural } \\
\text { losses if not } \\
\text { terminated } \\
\mathrm{NL} \\
\mathrm{n}\end{array}$} & \multirow{3}{*}{$\begin{array}{r}\text { Prevented } \\
\text { live births } \\
\text { P } \\
\text { n }\end{array}$} & \multirow{2}{*}{\multicolumn{2}{|c|}{$\begin{array}{r}\text { Live births if no } \\
\text { intervention } \\
\text { NI }\end{array}$}} & \multirow{3}{*}{$\begin{array}{r}\text { Babies } \\
\text { without } \\
\text { DS lost } \\
\text { UL } \\
\mathrm{n}\end{array}$} \\
\hline & & & & & & & & LB & & & & & \\
\hline & & & $\mathbf{n}$ & $\%$ & & & $\mathbf{n}$ & prev & & & $\mathbf{n}$ & prev & \\
\hline 1992 & 689656 & 1103 & 483 & $44 \%$ & 443 & 26 & 634 & 9.2 & 112 & 331 & 965 & 14.0 & 297 \\
\hline 1993 & 673467 & 1130 & 548 & $48 \%$ & 505 & 21 & 604 & 9.0 & 134 & 371 & 975 & 14.5 & 318 \\
\hline 1994 & 664726 & 1194 & 603 & $51 \%$ & 555 & 29 & 610 & 9.2 & 154 & 401 & 1011 & 15.2 & 339 \\
\hline 1995 & 648138 & 1193 & 648 & $54 \%$ & 589 & 39 & 565 & 8.7 & 167 & 422 & 987 & 15.2 & 351 \\
\hline 1996 & 649485 & 1302 & 722 & $55 \%$ & 666 & 34 & 602 & 9.3 & 195 & 471 & 1073 & 16.5 & 381 \\
\hline 1997 & 643095 & 1390 & 738 & $53 \%$ & 680 & 44 & 666 & 10.4 & 206 & 474 & 1140 & 17.7 & 375 \\
\hline 1998 & 635901 & 1298 & 703 & $54 \%$ & 640 & 24 & 634 & 10.0 & 195 & 445 & 1079 & 17.0 & 366 \\
\hline 1999 & 621872 & 1321 & 729 & $55 \%$ & 674 & 40 & 607 & 9.8 & 202 & 472 & 1079 & 17.3 & 373 \\
\hline 2000 & 604441 & 1369 & 808 & $59 \%$ & 742 & 29 & 598 & 9.9 & 228 & 514 & 1112 & 18.4 & 403 \\
\hline 2001 & 594634 & 1369 & 819 & $60 \%$ & 752 & 38 & 579 & 9.7 & 243 & 509 & 1088 & 18.3 & 412 \\
\hline 2002 & 565709 & 1451 & 889 & $61 \%$ & 805 & 48 & 598 & 10.6 & 257 & 548 & 1146 & 20.3 & 416 \\
\hline 2003 & 621469 & 1445 & 849 & $59 \%$ & 769 & 43 & 633 & 10.2 & 250 & 519 & 1152 & 18.5 & 373 \\
\hline 2004 & 639721 & 1675 & 1025 & $61 \%$ & 919 & 79 & 677 & 10.6 & 300 & 619 & 1296 & 20.3 & 407 \\
\hline 2005 & 645835 & 1815 & 1091 & $60 \%$ & 997 & 67 & 751 & 11.6 & 325 & 672 & 1423 & 22.0 & 408 \\
\hline 2006 & 669601 & 1877 & 1132 & $60 \%$ & 1028 & 82 & 767 & 11.5 & 337 & 691 & 1458 & 21.8 & 400 \\
\hline $1992-2006$ & 9567750 & 20932 & 11787 & $56 \%$ & 10764 & 643 & 9525 & 10.0 & 3304 & 7460 & 16985 & 17.8 & 5619 \\
\hline $1992-1996$ & 3325472 & 5922 & 3004 & $51 \%$ & 2758 & 149 & 3015 & 9.1 & 762 & 1996 & 5011 & 15.1 & 1686 \\
\hline 1997-2001 & 3099943 & 6747 & 3797 & $56 \%$ & 3488 & 175 & 3084 & 9.9 & 1074 & 2414 & 5498 & 17.7 & 1929 \\
\hline $2002-2006$ & 3142335 & 8263 & 4986 & $60 \%$ & 4518 & 319 & 3426 & 10.9 & 1468 & 3050 & 6476 & 20.6 & 2004 \\
\hline
\end{tabular}

Table 1 | Estimated prenatal screening performance 1991-2006 (2006 data are provisional), England and Wales. LB: All live births in England and Wales. D: Pregnancies diagnosed with Down syndrome before or after birth. PD: Pregnancies diagnosed with Down syndrome before birth (percentage of all diagnosed shown). T = Pregnancies prenatally diagnosed with Down syndrome terminated. M: Pregnancies prenatally diagnosed with Down syndrome that were recorded as ending in a miscarriage or stillbirth. LB: Live births of babies with Down syndrome. NL: Estimated number of terminated pregnancies that, if not terminated, would not have resulted in a live birth. P: Estimated 'prevented' live births of babies with Down syndrome ( $P=T-N L)$. UL: Estimated unaffected pregnancies lost due to invasive procedures following false screen-positive results. prev: Prevalence per 10,000. Unknown outcomes are apportioned proportional to prior known outcomes, consistent with the approach described by NDSCR. See text for further discussion of estimates. (Sources: Records of pregnancies diagnosed with Down syndrome, terminated, miscarried and live born are from the National Down Syndrome Cytogenetic Register ${ }^{[39]}$; records of all live births are from the UK Office for National Statistics ${ }^{[63]}$ ). 

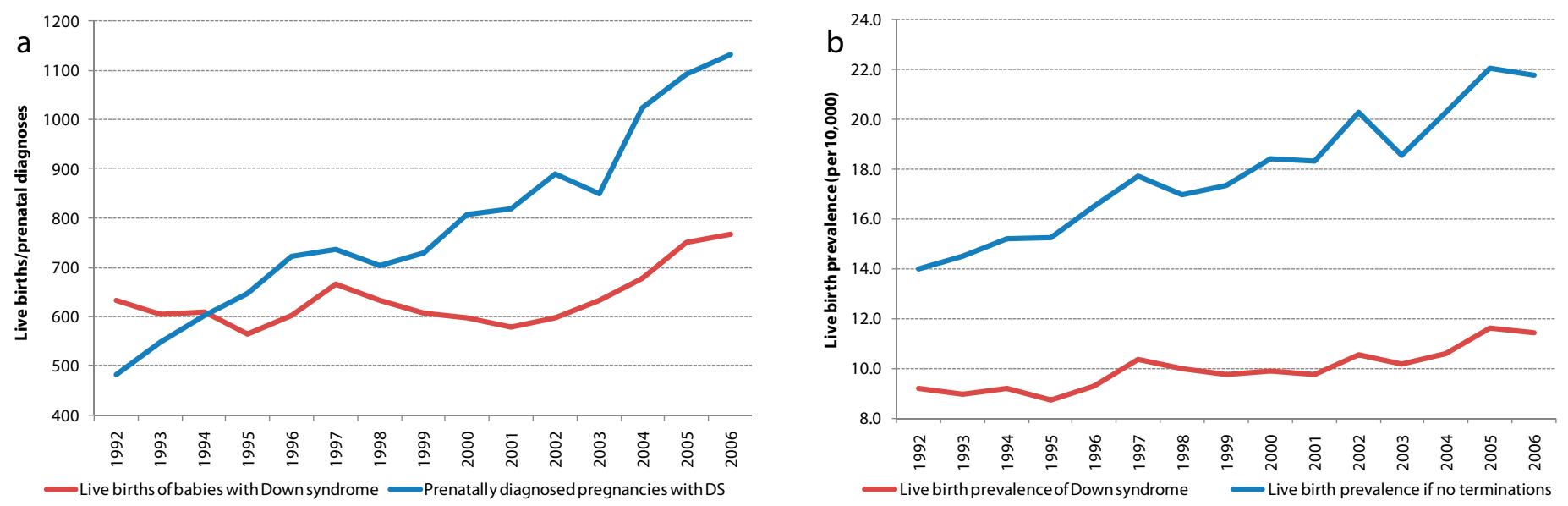

Figure 4 | Live births of babies with Down syndrome continue to rise. a Overall live births are at their highest for 15 years despite a nearly threefold increase in prenatally diagnosed pregnancies. $\mathbf{b}$ Live birth prevalence continues to increase as mothers increasingly choose childbirth later in life. In the absence of terminations, live birth prevalence would currently be estimated to be around 22 in 10,000 (1 in 455). This would be similar to recent live birth prevalence rates reported in Ireland (where termination is illegal) ${ }^{[62]}$.

loss rates of $43 \%$ and $23 \%$ for pregnancies diagnosed by CVS and amniocentesis, respectively ${ }^{[27]}$.

Records of outcomes for pregnancies screened positive and diagnosed without Down syndrome (false positives) are not maintained. We therefore estimated unaffected losses by assuming 45 losses for every 100 (1:2.2) prenatally diagnosed pregnancies with Down syndrome diagnosed by serum testing and/or ultrasound, and assuming 143 unaffected losses for every 100 (1:0.7) prenatal diagnoses predicted by maternal age alone. To allow for a possible improvement in practice due to increased use of the combined test in recent years, we assume that between 2001 and 2006, unaffected losses decrease to 31 for every 100 (1:3.2) prenatally diagnosed pregnancies with Down syndrome diagnosed by serum testing and/or ultrasound. These assumptions were derived from the detection and false positive rates observed using quadruple screening in practice in 14 UK hospitals (46,000 pregnancies; 88 with Down syndrome) and the predicted performance of maternal age screening from the same study ${ }^{[35]}$, and from rates observed for combined screening in a study involving 15 US centres (36,000 pregnancies; 92 with Down syndrome $)^{[4]]}$. In estimating these losses, we have assumed a loss rate of $1 \%$ as a consequence of diagnosis by either CVS or amniocentesis.

We concede that it is difficult to be confident about how accurately these assumptions reflect actual practice during the period examined. Data about the precise screening tests used and maternal choices following screen-positive test results have not been recorded (although the NDSCR has recently begun to collect data about screening tests). We have assumed rates observed in practice for the best performing (quadruple) blood test. For much of the period analysed, the double and triple tests were used widely and these are poorer performing $^{[22]}$. Ultrasound screening without blood markers also perform worse than quadruple screening ${ }^{[22]}$. It is conceivable that actual performance could be closer to that predicted by some modelling studies, though evidence seems to suggest that this is unlikely in practice ${ }^{[35-37]}$. We have been cautious about overestimating the losses of unaffected babies and assumed $1 \%$ loss rates for both amniocentesis and CVS. If, in practice, CVS is associated with an additional $1 \%$ risk, then we would estimate recent losses of babies without Down syndrome to be around 50\% higher in recent years (around 600 annually).

With these caveats in mind, the following observations can be made. Firstly,

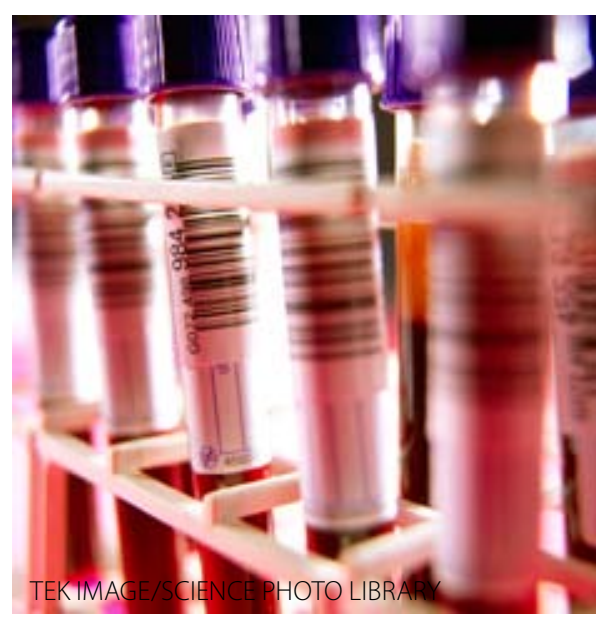

although public health policies promote prenatal screening to support selective termination, more children with Down syndrome are being born than 15 years ago and live birth prevalence has risen (FIGURE 4). Over this period, screening policies have reduced live births by an estimated 44\% (from 16,985 in the absence of intervention to 9,525). Parents might have made different choices in the absence of screening, but it is nonetheless interesting to note that choices to raise families later in life have increased expected live birth prevalence $^{[42]}$ (in the absence of intervention) by an estimated 50\% (from 14.0 to 21.8 in 10,000) between 1992 and 2006.

We conclude that current screening policies appear to be reducing the live births of babies with Down syndrome in England and Wales each year by around 660 and leading to the losses of 400 babies who did not have Down syndrome. Adopting firsttrimester combined screening (as recommended by the UK National Institute for Health and Clinical Excellence and the American College of Obstetricians and Gynecologists and recently adopted in Scotland) will lead to the detection of more babies with Down syndrome who would not naturally survive to term. If the excess loss rate following CVS is higher than that following amniocentesis in practice, then adopting first-trimester combined screening may increase the number of babies without Down syndrome lost.

\section{Rightful lives}

Quality of life for most people with Down syndrome in many wealthy nations has improved dramatically over the past 40 


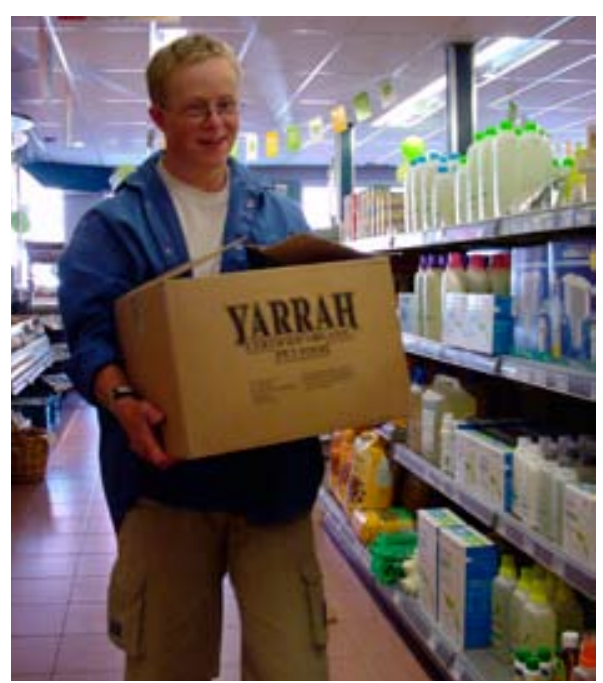

years. The additional chromosome is still there, but the support provided them by their communities has changed. Their medical needs are mostly well understood $^{[43-46]}$. Knowledgeable medical care has raised average life expectancy for people with Down syndrome born in many developed countries today to 60 years (up from 12 years in 1949) and increasing numbers now live beyond 70 years ${ }^{[47-50]}$. More young people with Down syndrome are gaining access to effective education and therapies and achieving better levels of literacy and improved communication skills $^{[51]}$. More adults with Down syndrome are gaining useful and rewarding employment and exercising greater control over their lives. There is much still to do and for an important minority significant additional challenges remain, but the progress people with Down syndrome have made is remarkable.

\section{Predicting quality of life}

Knowing that someone has 47 chromosomes rather than 46 does not enable

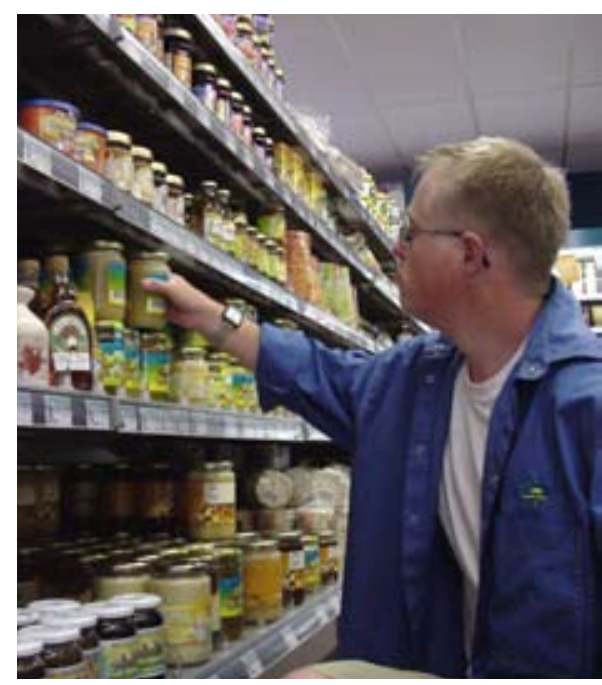

precise prediction of quality of life. Some babies with Down syndrome are born with congenital heart defects (around 44\%) and many are not ${ }^{[52]}$, some adults develop dementia (9\% up to the age of 49 years, $18 \%$ of those aged $50-54$, and $35 \%$ of those aged 55-59) and many do not ${ }^{[50]}$, some children experience fewer learning difficulties and some more - the chromosome count remains the same. By contrast, Down syndrome appears to offer protection against some cancers ${ }^{[53]}$ and cardiovascular disease $^{[54]}$.

Some people with Down syndrome find employment as film and TV actors, write books, and become competent musicians and talented athletes. However, some people with Down syndrome find obtaining employment difficult and some will only be able to fulfil less skilled roles in work. People with Down syndrome make positive contributions to family and community life and often form loving and caring relationships. They are very rarely antisocial, violent or criminal.

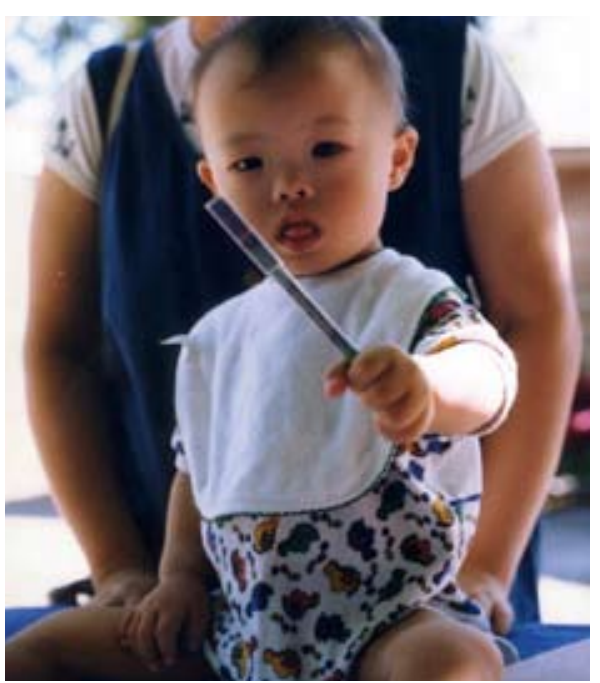

\section{Whose quality of life?}

As far as we are aware, no large study of the views of people living with Down syndrome about their quality of life has been conducted. Anecdotally, people with Down syndrome do not appear to consider their condition a source of suffering ${ }^{[55,56]}$. Much of what effects quality of life for people with Down syndrome perhaps results from society's behaviour towards them rather than necessarily the condition itself.

\section{Should screening continue?}

The authors of this editorial do not consider a diagnosis of Down syndrome to be a sufficient reason to justify termination and so disagree with the basic premise for prenatal screening for Down syndrome. Harming babies who do not have Down syndrome in the process seems to us unjustifiable. And we are not alone in our ethical concerns. A survey of 40 randomly selected research ethics committees found that $86 \%$ of 77 committee members responding from 28 committees did not
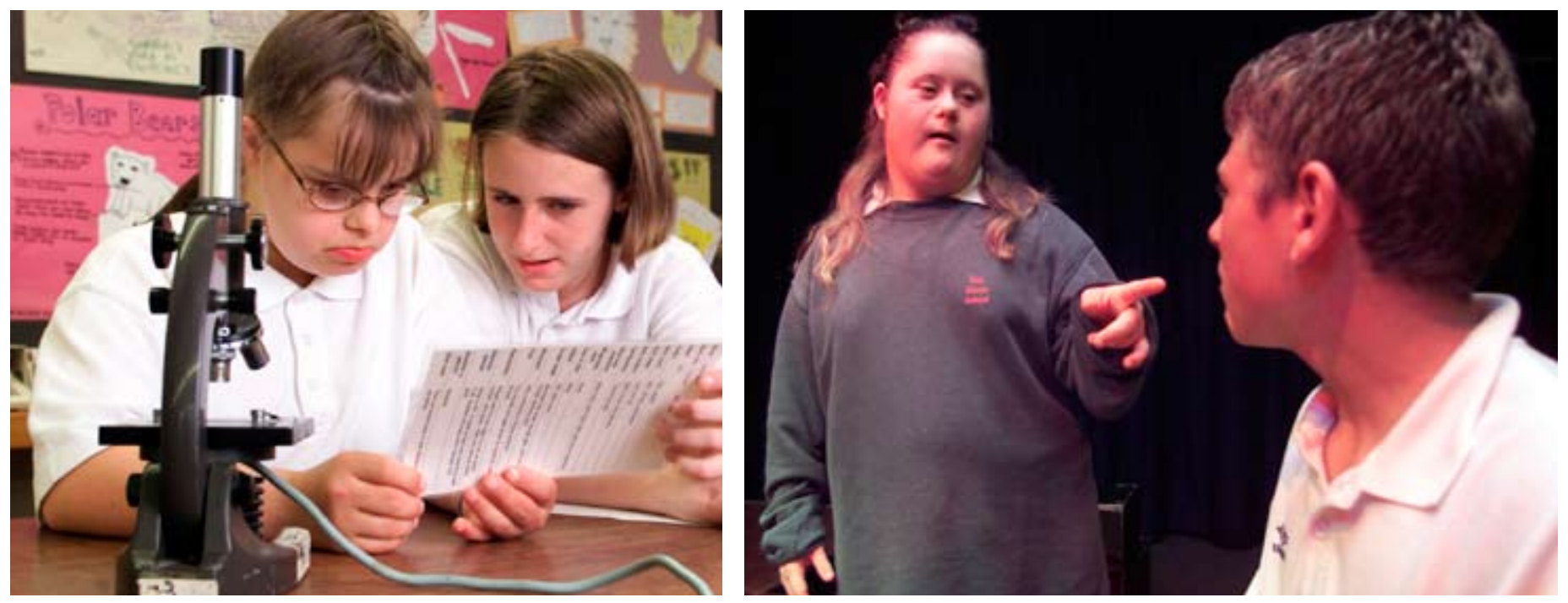

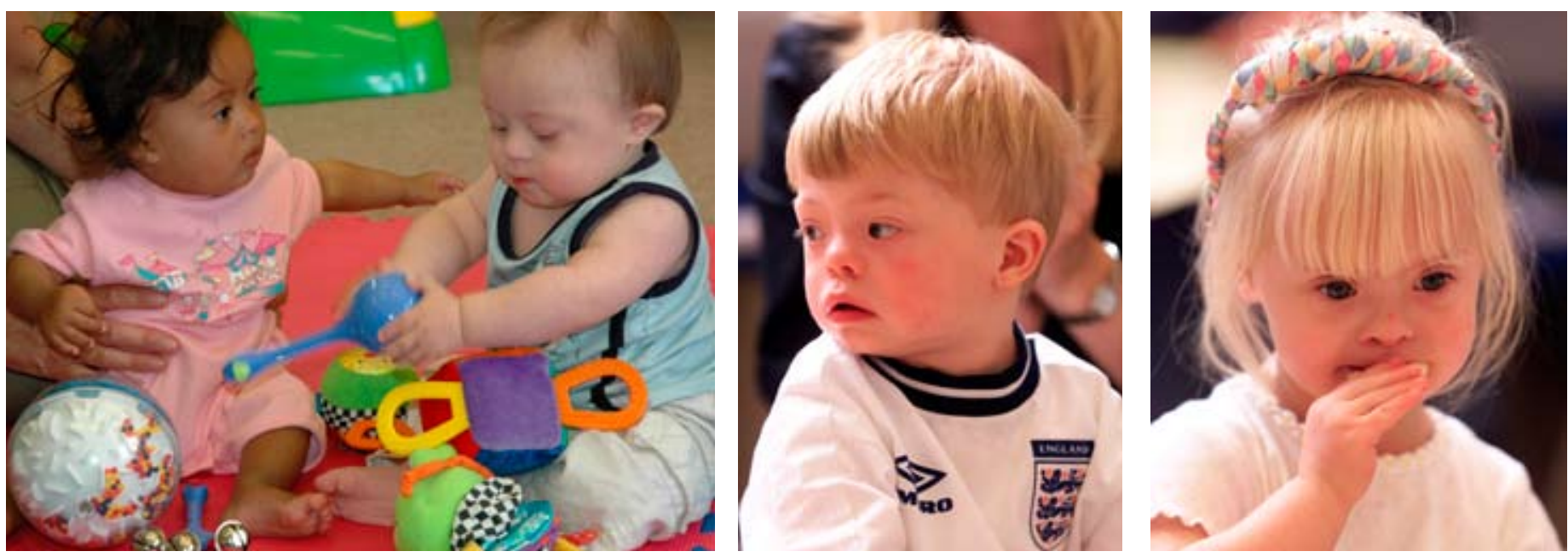

consider current screening practice (and associated risks) ethically acceptable in order to avoid the birth of a person with the clinical features associated with Down syndrome ${ }^{[57]}$.

\section{The future}

Public health policies do not currently target most other genetic causes of learning difficulties or treatable medical conditions for selective termination.

A race is on to reliably extract foetal DNA from maternal blood samples ${ }^{[58,59]}$. Meanwhile, another race is heading towards reducing the costs of whole genome sequencing to under $\$ 1,000^{[\mathrm{REF} 60]}$. When these two races collide, it will be possible to provide expectant couples with a comprehensive report of thousands of risk factors for a myriad of possible outcomes in life that may (or may not) influence quality of life ${ }^{[61]}$.

"Once fetal DNA can be non-invasively obtained, screening practices will be able to generate a massive amount of information

1. American College of Obstetricians and Gynecologists. New Recommendations for Down Syndrome: Screening Should Be Offered to All Pregnant Women. Washington, DC: ACOG; 2007, Jan [cited 2008 Jul 21]. Available from: http://www. acog.org/from_home/publications/press_releases/nr06-30-04.cfm

2. American College of Obstetricians and Gynecologists. ACOG Issues Position on First-Trimester Screening Methods. Washington, DC: ACOG; 2004, Jun [cited 2008 Jul 21]. Available from: http://www.acog.org/from_home/publications/press_releases/ nro6-30-04.fm

3. National Collaborating Centre for Women's and Children's Health. Antenatal care: routine care for the healthy pregnant woman. London, UK: RCOG Press; 2008 Mar [cited 2008 Jul 21]. Available from: http://www.nice.org.uk/CG62

4. Alderson, P. Prenatal screening, ethics and Down's syndrome: a literature review. Nursing Ethics. 2001;8(4):360-374.

5. Alderson, P. Prenatal screening, Down's syndrome: cost, quality and value of life. Social Science and Medicine. 2001;53:627-638. of uncertain importance. These data might cause more harm than good..."661]

Faced with choices between (say) estimated risks for autism and for dementia, how will couples make informed choices? How many pregnancies will couples be expected to 'reject' in their efforts to deliver the 'best' baby possible? What effect will these practices have on the people who 'slip through the net' and are born with 'undesirable' attributes?

Prenatal screening for Down syndrome was introduced with inadequate public and political debate 20 years ago. When widespread prenatal whole genome screening becomes a possibility, many of the troubling issues raised by our experiences of screening for Down syndrome will be brought into sharper focus. The technology may be with us within 5 years. The authors believe that wider public debate should begin now.

To contribute to this debate, this journal would welcome correspondence, reports,

6. Brown RI. The effects of quality life models on the development of research and practice in the field of Down syndrome. Down Syndrome Research and Practice. 1998;5(1);39-42. Available from: http://www.down-syndrome.org/reviews/74/

7. Bramwell R, West $H$, Salmon P. Health professionals' and service users' interpretation of screening test results: experimental study. British Medical Journal. 2006;333(7562):284-287. doi:10.1136/bmj.38884.663102.AE

8. Roberts CD, Stough LD, Parrish LH. The role of genetic counseling in the elective termination of pregnancies involving fetuses with disabilities. Journal of Special Education. 2002;36(1):4855.

9. Skotko B. Mothers of children with Down syndrome reflect on their postnatal support. Pediatrics. 2005;115(1):64-77.

10. Skotko B, Bedia RC. Postnatal support for mothers of children with Down syndrome. Mental Retardation. 2005;43(3):196-212.

11. Skotko BG. Prenatally diagnosed Down syndrome: mothers who continued their preg- reviews, opinion and essays on all aspects of genetic screening in the context of modern opportunities for people with Down syndrome.

The views expressed in this editorial are those of the authors and may not necessarily reflect those of individual members of the Editorial Board.

\section{Acknowledgements}

The authors thank the many reviewers who have commented on earlier drafts of this editorial.

Frank Buckley (frank.buckley@downsed.org) and Sue Buckley (sue.buckley@downsed.org) are at Down Syndrome Education International, Portsmouth, UK, and Down Syndrome Education USA, Irvine, CA, USA. SB is also at the Department of Psychology, University of Portsmouth, UK. SB is the mother of an adopted daughter with Down syndrome who is sister to FB.

\section{doi:10.3104/editorials.2087}

nancies evaluate their health care providers. American Journal of Obstetrics and Gynecology. 2005;192(3):670-7.

12. Lawson KL, Turriff-Jonasson SI. Maternal serum screening and psychosocial attachment to pregnancy. Journal of Psychosomatic Research. 2006;60(4):371-378. doi:10.1016/j.jpsychores.2006.01.010

13. Van den Bergh BR, Mulder EJ, Mennes M, Glover V. Antenatal maternal anxiety and stress and the neurobehavioural development of the fetus and child: links and possible mechanisms. A review. Neuroscience and Biobehavioral Reviews. 2005;29(2):237-58.

14. Talge NM, Neal C, Glover V; Early Stress, Translational Research and Prevention Science Network: Fetal and Neonatal Experience on Child and Adolescent Mental Health. Antenatal maternal stress and long-term effects on child neurodevelopment: how and why? Journal of Child Psychology and Psychiatry. 2007;48(34):245-61.

15. Korenromp MJ, Page-Christiaens GC, van den Bout J, Mulder EJ, Hunfeld JA, Potters CM, Erwich JJ, van Binsbergen CJ, Brons JT, Beekhuis 
JR, Omtzigt AW, Visser GH. A prospective study on parental coping 4 months after termination of pregnancy for fetal anomalies. Prenatal Diagnosis. 2007;27(8):709-16.

16. Cuskelly M, Hauser-Cram $P$, Van Riper M. Families of children with Down syndrome: What we know and what we need to know. Down Syndrome Research and Practice. Advance Publication Online, available at: http://www.down-syndrome. org/reviews/2079/

17. Skotko BG, Levine SP. What the other children are thinking: brothers and sisters of persons with Down syndrome. American Journal of Medical Genetics Part C: Seminars in Medical Genetics. 2006;142C(3):180-6.

18. Reynolds TM. Down's syndrome screening: a controversial test, with more controversy to come! Journal of Clinical Pathology. 2000;53:893898.

19. Meire HB. Is ultrasound as useful as we think? Ultrasound. 2007;15(3):177-184.

20. Morris J, Mutton D, Alberman E. Corrections to maternal age-specific live birth prevalence of Down's syndrome. Journal of Medical Screening. 2005;12(4):202.

21. Wald NJ, Cuckle HS, Densem JW, Nanchahal K, Royston P, Chard T, Haddow JE, Knight GJ, Palomaki GE, Canick JA. Maternal serum screening for Down's syndrome in early pregnancy. British Medical Journal. 1988;297(6653): 883-887. Available from: http://www.pubmedcentral.nih.gov/pagerender. fcgi?artid=1834444\&pageindex $=1$

22. Wald NJ, Rodeck C, Hackshaw AK, Walters J, Chitty L, Mackinson AM. First and second trimester antenatal screening for Down's syndrome: the results of the Serum, Urine and Ultrasound Screening Study (SURUSS). Health Technology Assessment. 2003;7(11). Available from: http://www. hta.ac.uk/907

23. Wald NJ, Rodeck C, Hackshaw AK, Rudnicka A. SURUSS in perspective. Seminars in Perinatology. 2005;29:225-235. doi:10.1053/j.semperi.2005.05.006

24. Wald NJ. Guidance on terminology. Journal of Medical Screening. 2006;13(1):53.

25. Chen J, Heffley D, Beazoglou T, Benn PA. Utilization of amniocentesis by women screening positive for Down syndrome on the secondtrimester triple test. Community Genetics. 2000;3:24-30.

26. Hassold T, Hunt P. To err (meiotically) is human: the genesis of human aneuploidy. Nature Reviews Genetics. 2001:2:280-291. doi:10.1038/35066065

27. Morris JK, Wald NJ, Watt HC. Fetal loss in Down syndrome pregnancies. Prenatal Diagnosis. 1999:19:142-145.

28. Savva GM, Morris JK, Mutton DE, Alberman E. Maternal age-specific fetal loss rates in Down syndrome pregnancies. Prenatal Diagnosis. 2006;26(6):499-504

29. Alfirevic Z, Sundberg K, Brigham S. Amniocentesis and chorionic villus sampling for prenatal diagnosis. Cochrane Database of Systematic Reviews. 2003, Issue 3. Art. No.: CD003252. doi:10.1002/14651858.CD003252

30. Mujezinovic F, Alfirevic Z. Procedure-related complications of amniocentesis and chorionic villous sampling: a systematic review. Obstetrics and Gynecology. 2007;110(3):687-94.

31. Guidelines and Audit Committee of the Royal College of Obstetricians and Gynaecologists. Amniocentesis and chorionic villus sampling. RCOG Guideline No. 8 (revised). 2005 Jan: London, UK: Royal College of Obstetricians and Gynaecologists. Available from: http://www.rcog.org uk/resources/Public/pdf/aminiocentesis_chorionicjan2005.pdf
32. Royal College of Obstetricians and Gynaecologists. Amniocentesis: what you need to know. 2006 Jun: London, UK: Royal College of Obstetricians and Gynaecologists. Available from: http://www.rcog.org.uk/index.asp?PagelD=1556

33. American College of Obstetricians and Gynecologists. Diagnosing birth defects (ACOG Patient Education). 2005 Apr: Washington, DC, USA : American College of Obstetricians and Gynecologists. Available from: http://www.acog.org/publications/patient_education/bp164.cfm

34. Royal College of Obstetricians and Gynaecologists. Chorionic villus sampling (CVS): what you need to know. 2006 Jun: London, UK: Royal College of Obstetricians and Gynaecologists. Available from: http://www.rcog.org.uk/index.asp?PagelD=1557

35. Wald NJ, Huttly WJ, Hackshaw AK. Antenatal screening for Down's syndrome with the quadruple test. The Lancet. 2003;361:835-836.

36. Howe DT, Gornall R, Wellesley D, Boyle T, Barber J. Six year survey of screening for Down's syndrome by maternal age and mid-trimester ultrasound scans. British Medical Journal. 2000;320:606-610.

37. Wellesley D, Boyle T, Barber J, Howe DT. Retrospective audit of different antenatal screening policies for Down's syndrome in eight district general hospitals in one region. British Medical Journal. 2002;325:15. doi:10.1136/ bmj.325.7354.15

38. Wald NJ, Huttly WJ, Hennessy CF. Down's syndrome screening in the UK in 1998. The Lancet. 1999:354(7354):1264.

39. The National Down Syndrome Cytogenetic Register. The National Down Syndrome Cytogenetic Register 2006 Annual Report. London, UK: Wolfson Institute of Preventive Medicine; 2008 April [cited $2008 \mathrm{Jul}$ ]. Available from: http://www. wolfson.qmul.ac.uk/ndscr/reports/NDSCRreport06.pdf

40. EUROCAT Central Registry. Special Report: Prenatal Screening Policies in Europe. Newtownabbey, UK: University of Ulster; 2005 [cited $2008 \mathrm{Jul}$ 21]. Available from: http://www.eurocat.ulster. ac.uk/pdf/Special-Report-Prenatal-Diagnosis.pdf

41. Malone FD, Canick JA, Ball RH, Nyberg DA, Comstock $\mathrm{CH}$, Bukowski R, Berkowitz RL, Gross SJ, Dugoff L, Craigo SD, Timor-Tritsch IE, Carr SR, Wolfe HM, Dukes K, Bianchi DW, Rudnicka AR, Hackshaw AK, Lambert-Messerlian G, Wald NJ, D'Alton ME; First- and Second-Trimester Evaluation of Risk (FASTER) Research Consortium. First-trimester or second-trimester screening, or both, for Down's syndrome. New England Journal of Medicine. 2005;353(19):2001-11.

42. Crane $E$, Morris JK. Changes in maternal age in England and Wales - implications for Down syndrome. Down Syndrome Research and Practice. 2006;10(1);41-43. Available from: http://www. down-syndrome.org/reports/304/

43. American Academy of Pediatrics. Committee on Genetics. American Academy of Pediatrics: Health supervision for children with Down syndrome. Pediatrics. 2001;107(2):442-9.

44. Van Cleve SN, Cohen WI. Part I: clinical practice guidelines for children with Down syndrome from birth to 12 years. Journal of Pediatric Health Care. 2006;20(1):47-54.

45. Van Cleve SN, Cannon S, Cohen WI. Part II: Clinical Practice Guidelines for adolescents and young adults with Down Syndrome: 12 to 21 Years. Journal of Pediatric Health Care. 2006;20(3):198-205

46. Cohen WI. Current dilemmas in Down syndrome clinical care: celiac disease, thyroid disorders, and atlanto-axial instability. American Journal of Medical Genetics: Part C - Seminars in Medical Genetics. 2006;142C(3):141-8.
47. Glasson EJ, Sullivan SG, Hussain R, Petterson BA Montgomery PD, Bittles AH. The changing survival profile of people with Down's syndrome: implications for genetic counselling. Clinical Genetics. 2002;62(5):390-393.

48. Bittles AH, Glasson EJ. Clinical, social, and ethical implications of changing life expectancy in Down syndrome. Developmental Medicine and Child Neurology. 2004;46(4):282-6.

49. Krinsky-McHale SJ, Devenny DA, Gu H, Jenkins EC, Kittler P, Murty VV, Schupf N, Scotto L, Tycko B, Urv TK, Ye L, Zigman WB, Silverman W. Successful aging in a 70-year-old man with Down syndrome: a case study. Intellectual and Developmental Disabilities. 2008;46(3):215-28.

50. Coppus A, Evenhuis H, Verberne GJ, Visser F, van Gool P, Eikelenboom P, van Duijin C. Dementia and mortality in persons with Down's syndrome. Journal of Intellectual Disability Research. 2006;50(10):768-777.

51. Buckley SJ, Bird G, Sacks B, Archer T. A comparison of mainstream and special education for teenagers with Down syndrome: Implications for parents and teachers. Down Syndrome Research and Practice. 2006;9(3);54-67.

52. Freeman SB, Bean LH, Allen EG, Tinker SW, Locke $A E$, Druschel C, Hobbs CA, Romitti PA, Royle MH, Torfs CP, Dooley KJ, Sherman SL. Ethnicity, sex and the incidence of congenital heart defects: a report from the National Down Syndrome Project. Genetics in Medicine. 2008;10(3):173-80.

53. Sussan TE, Yang A, Li F, Ostrowski MC, Reeves $\mathrm{RH}$. Trisomy represses Apc(Min)-mediated tumours in mouse models of Down's syndrome. Nature. 2008;451(7174):73-5. doi:10.1038/nature06446

54. Draheim CC, McCubbin JA, Williams DP. Differences in cardiovascular disease risk between nondiabetic adults with mental retardation with and without Down syndrome. American Journal on Mental Retardation. 2002;107(3):201-11.

55. Kingsley J, Levitz M. Count us in: growing up with Down syndrome. 2007. 1st Reprint Ed. San Diego, CA, USA: Harvest Books.

56. Buckley SJ. Living with Down syndrome. 2000. Portsmouth, UK: The Down Syndrome Educational Trust. Available from: http://www.down-syndrome.org/information/development/overview/

57. Reynolds TM. Down's syndrome screening is unethical: views of today's research ethics committees. Journal of Clinical Pathology. 2003;56:268-270.

58. Avent ND, Plummer ZE, Madgett TE, Maddocks DG, Soothill PW. Post-genomics studies and their application to non-invasive prenatal diagnosis. Seminars in Fetal and Neonatal Medicine. 2008;13(2):91-8.

59. Hahn S, Zhong XY, Holzgreve W. Recent progress in non-invasive prenatal diagnosis. Seminars in Fetal and Neonatal Medicine. 2008;13(2):57-62.

60. Service RF. Gene sequencing: The race for the \$1000 genome. Science. 2006;311(5767):1544-6.

61. Shuster E. Microarray genetic screening: a prenatal roadblock for life? The Lancet. 2007;369(9560):526-9

62. Down syndrome prevalence for the following registries: Cork and Kerry, Dublin, Galway, SE Ireland, from 2002-2006. EUROCAT Website Database (data uploaded Apr 7, 2008). Available from: http://www.bio-medical.co.uk/eurocatlive

63. National Statistics. Birth statistics: Review of the Registrar General on births and patterns of family building in England and Wales, 2006. Newport, UK: Office for National Statistics. Available from: http://www.statistics.gov.uk/downloads/theme_population/FM1_35/FM1_No35.PDF 